\title{
A methodological proposal for the recovery of palynomorphs from snow and ice samples
}

\author{
Luiz Antonio da Costa Rodrigues ${ }^{1}{ }^{(0)}$, Kamila da Matta Agostini ${ }^{1}$, Alexandre Santos de Alencar ${ }^{2}(\mathbb{D}$, \\ Cláudia Barbieri Ferreira Mendonça ${ }^{1} \mathbb{D}$, Marcelo Araújo de Carvalho ${ }^{1} \mathbb{D}$ and Vania Gonçalves-Esteves ${ }^{1^{*}}$ (i)
}

Received: January 3, 2018

Accepted: March 5, 2018

\begin{abstract}
The procedures for a set of techniques to recover grains of pollen 26 and spores from liquid samples are described. Liquefied samples of matrices, such as melting lakes, snow and ice, can provide a record of climatic and environmental events at different geographic and temporal scales. The need for standardization of techniques was demonstrated in research carried out with matrices of snow and water of thawing lakes and snow collected on King George and Joinville islands (Antarctica). The use of the methods described can permit increased rescue of palynomorphs from liquid matrices, thereby adding greater reliability to palynological data and its use as a biotracer of environmental events. Methods of sieving and centrifugation were tested, and sieving proved more efficient for the matrices analyzed.
\end{abstract}

Keywords: Antarctica, ice, spores, snow, technique to recover grains of pollen

Climatic studies are tasks that require an interdisciplinary approach, especially in the identification of efficient indicators. Global climate change and the identification of potential impacts of anthropic actions in the natural environment require the use of different matrices and tracers suitable for point, qualitative, inferential and temporal analyses.

On a global scale, the poles serve as indicator repositories since local and global events can carry and deposit chemical, biological and physical traces in these regions (Goldemberg 2011). Environmental matrices, such as melted-water, snow and ice, from polar-regions can provide evidence of recent as well as long-standing climatic environmental events.
The use of such matrices has broad application in the study of climate change and anthropic impact through Remote Sensing (Magalhães et al. 2011; Sotille et al. 2016) and Glaciochemistry (Potocki et al. 2013; Schwanck et al. 2016).

The Arctic and Antarctica are regions that respond rapidly to global climate change (Souza Junior et al. 2016). The use of chemical and physical signature to identify particulate matter in frozen regions is widely employed, however, the use of tracers belonging to particulates < PM10 is still scarce among the work done in these regions. In this regard, the use of pollen and spore grains as biotracers can be effective in identifying the origin of particulate matter deposited in environmental samples. Works such

1 Museu Nacional, Universidade Federal do Rio de Janeiro, 20940-040, São Cristóvão, RJ, Brazil

2 Universidade Veiga de Almeida, 20271-020, Rio de Janeiro, RJ, Brazil

* Corresponding author: esteves.vr@gmail.com 


\section{Luiz Antonio da Costa Rodrigues, Kamila da Matta Agostini, Alexandre Santos de Alencar, Cláudia Barbieri Ferreira Mendonça, Marcelo Araújo de Carvalho, Vania Gonçalves-Esteves}

as those performed by Linskens et al. (1993), Harmata \& Olech (1991), Vergamini et al. (2006) and Parnikoza et al. (2011) have documented the atmospheric transport of pollen grains; however, they did not analyze matrices of water, snow or ice.

The morphology and morphometry of such structures have been widely used as auxiliary tools of botanical taxonomy. They also have applications in the field of ecology, including aerobiological (Anderson et al. 1998), allergenic (Vergamini et al. 2006) and paleoenvironmental studies (Donizeti 2004; Héguy et al. 2008). Pioneering palynological analyses of snow and water from melting lakes showed positive results for pollen grains and spores of plants with geographic distributions in South America (Agostini et al. 2017). Research development in the Laboratório de Palinologia Professor Álvaro Xavier Moreira analyzes samples from different matrices of the Antarctic Continent. For the recovery and identification of palynomorphs in liquid samples, the acetolytic method was used experimentally. After experiencing difficulty recovering pollen grains, some crucial issues were identified: 1 ) limited pollen 68 concentration in the sample volume; 2) risk of contamination by palynomorphs during the process; and 3) loss of more fragile grains as a result of acid treatment. In this context, a need for methodological adequacy that permits the wide recovery of pollen grains and spores was recognized.

Considering the need for standardization of the methods for palynological treatment of liquid samples, two methods of preparation were tested. In a biological safety booth, a total volume of $350 \mathrm{~mL}$ of ultrapure water was fractionated in $50 \mathrm{~mL}$ Falcon tubes, with $150 \mathrm{~mL}$ being used for sieving and $200 \mathrm{~mL}$ for centrifugation.

Method I - Separation by centrifugation: For the centrifugation method, four Falcon tubes $(50 \mathrm{~mL})$ were initially used. The tubes (T1, T2, T3 and T4) were filled with $50 \mathrm{~mL}$ of Milli-Q ${ }^{\circledR}$ ultrapure water, totaling $200 \mathrm{ml}$. Subsequently, 1 pellet of Lycopodium was diluted in T1 and T2. Dilution was performed in sterile Becker with $1 \mathrm{ml}$ of $10 \%$ hydrochloric acid-HCl. Lycopodium was used to allow the counting and verification of spore rescue. Tubes T3 and T4 constituted the control and received $1 \mathrm{ml}$ of $10 \% \mathrm{HCl}$ each, totaling $51 \mathrm{~mL}$ of solution per tube.

The samples were separated into two groups; Group 1 (G1) consisting of 1 control tube (T3) and 1 tube containing a Lycopodium pellet (T1), Group 2 (G2) consisting of 1 control tube (T4) and 1 tube containing a Lycopodium pellet (T2). The volume of each tube was fractionated in Falcon tubes (10 $\mathrm{mL}$ ) and then centrifuged in a centrifuge with a fixed angle rotor. The $\mathrm{G} 1$ was centrifuged at $2.000 \mathrm{xg}$ (10 minutes) and the $\mathrm{G} 2$ was centrifuged at $4.000 \mathrm{xg}$ (10 minutes). After this procedure, the supernatant was discarded for total volume reduction. After removal of excess volume, the tubes were capped in a Becker with absorbent paper for 60 minutes. After drying, a cube of glycerinated gelatin, prepared according to the method of Kisser (1935 apud Erdtman 1952), measuring approximately $3 \mathrm{~mm}$, was introduced into each tube. Using spiral movements with a stylet, the cubes were moved across the entire inner surface of the tube for greater adherence of the Lycopodium. The cube was then dragged to the edge of the tube, removed and placed on a slide for fractionation into three equal parts. After fractionation, the gelatin was distributed onto three glass slides, heated to the melting point of the gelatin, covered with coverslips and fanned with paraffin.

Method II - Separation by sieve: For the sieve separation method, three Falcon tubes $(50 \mathrm{~mL})$ were used. The tubes (T1, T2 and T3) were filled with $50 \mathrm{~mL}$ of Milli- $\mathrm{Q}^{\circ}$ ultrapure water totaling $150 \mathrm{~mL}$. Subsequently, tubes T2 and T3 received a Lycopodium pellet. The pellets were pre-diluted in a sterile Becker with $1 \mathrm{~mL}$ of $10 \%$ hydrochloric acid- $\mathrm{HCl}$. In this method, $\mathrm{T} 1$ constituted the control and did not receive a Lycopodium pellet. In the separation process, sieves constructed with tubes of PVC (polyvinyl chloride) pipe and polyethylene mesh with a porosity of $6 \mu \mathrm{m}$ were used.

For the construction of the sieves, a mesh fraction measuring $4 \mathrm{x} 4 \mathrm{~cm}$ was used, which was later fused to the tube by heating on a hot plate (Fig. 1). Single sieves were used for each sample, one unit for the control group (T1) and two units for tubes $\mathrm{T} 1$ and $\mathrm{T} 2$. For the rescue of the Lycopodium spores, glycerinated gelatin cubes measuring approximately $3 \mathrm{~mm}$ in size, prepared according to Kisser (1935 apud Erdtman 1952) were used. The sieves were unique to each sample. Each sieve had its extension covered by a cube of gelatin with the aid of a stylet. Subsequently, the complex (gelatin + Lycopodium) was removed from the sieve and placed on a slide. The cube of gelatin was fractionated into three equal parts and was distributed onto three glass slides, heated to the melting point of the gelatin, covered by coverslips and fanned with paraffin. After the preparation, analyses were performed using transmitted white-light microscopy using a Zeiss Axiostar plus microscope. Four scans were performed per slide, oriented longitudinally and parallel in the optical field at 400X magnification. The results showed that the method of preparation by centrifugation (Method I) recovered a total of 48 Lycopodium spores after centrifugation at 2,000 x g (10 minutes) and 52 spores at $4,000 \times \mathrm{g}$ (10 minutes). The sieving method (Method II) recovered a total of 408 spores of Lycopodium. The control group exhibited negative results for both methods tested. The use of sieving for palynomorph recovery from liquid samples was more efficient than the centrifugation method. Furthermore, this process does not prevent, after separation, the recovery of palynomorphs in solution for chemical treatment (e.g., acetolysis). The use of the sieving method for pollen rescue showed a greater recovery of Lycopodium spores, and represents a methodological contribution to the use of palynomorphs as biotracers in samples of snow, ice and water. 


\section{A methodological proposal for the recovery of palynomorphs \\ from snow and ice samples}
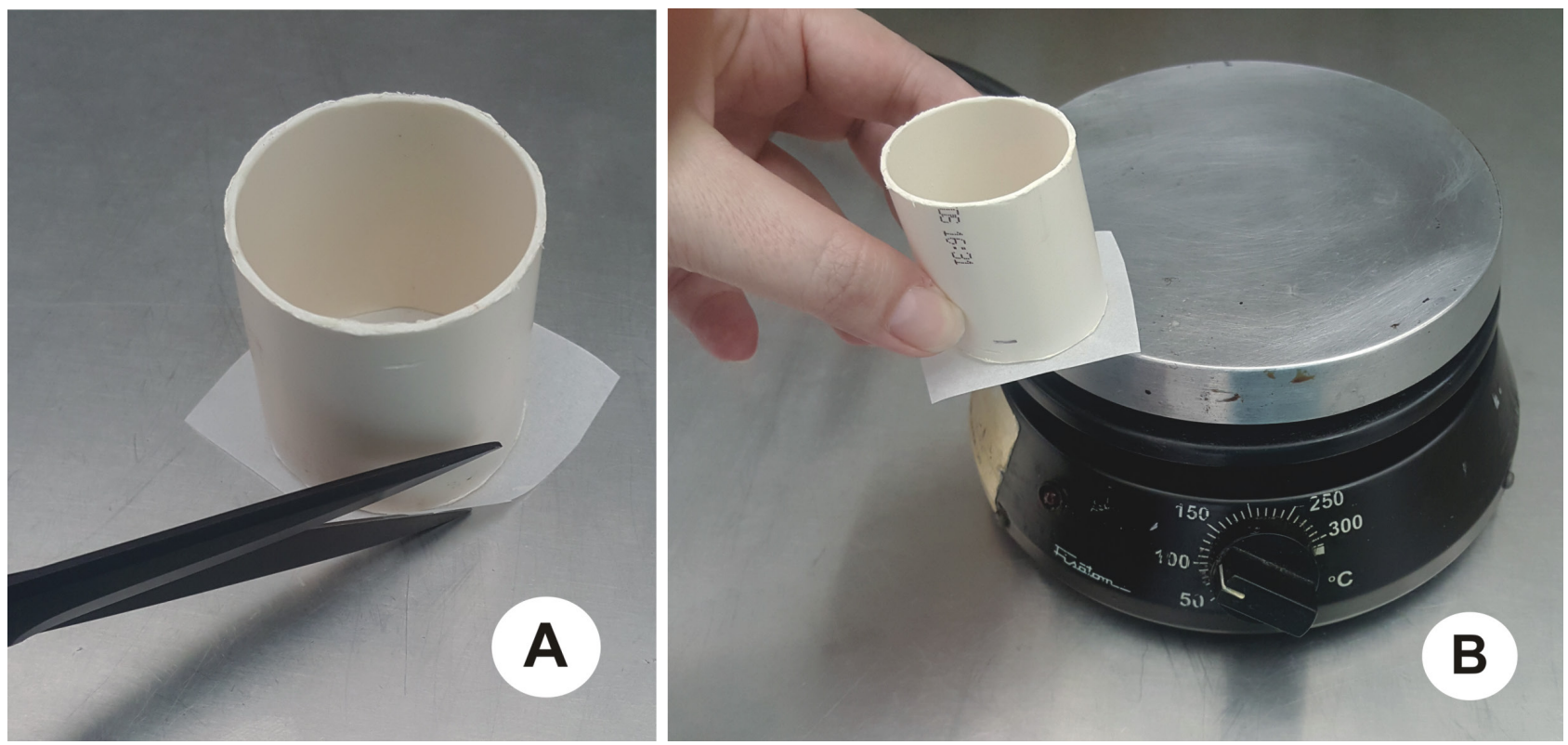

Figure 1. A. Cutting of the mesh; B. fusion with tube on a hot place.

\section{Acknowledgements}

We thank the Programa Antártico Brasileiro (Brazilian Antarctic Program; PROANTAR/CNPq) for collecting the material; the Laboratório de Radioecologia e Mudanças Globais (Laboratory of Radioecology and Global Change; LARAMG). The authors, Gonçalves-Esteves, V. Mendonça, CBF. and Carvalho, M.A. thanks to the CNPq (Conselho Nacional de Desenvolvimento Científico e Tecnológico) for a Productivity Grant and the FAPERJ (Fundação de Amparo à Pesquisa do Estado do Rio de Janeiro) for financial support.

\section{References}

Agostini KM, Rodrigues LAC, Mendonça CBF, Gonçalves-Esteves V. 2017 Analysis of exotic pollen grains and spores from thawing lakes of King George Island, Antarctic Peninsula. Review Paleobotany and Palynology 245: 1-9.

Anderson H, Leon AP, Bland J, Bower J, Emberlin J, Strachan D. 1998. Air pollution, pollens, and daily admissions for asthma in London 1987-92. Thorax 53: 842-848.

Donizeti AO, Mendonça Filho JG, Carvalho MA, Menezes TR, Lana CC, Brenner WW. 2004. Novo método de preparação palinológica para aumentar a recuperação de Dinoflagelados. Revista Brasileira de Paleontologia 7: 169-175.

Erdtman G. 1952. Pollen morphology and plant taxonomy-Angiosperms. Stockholm, Almqvisit \& Wiksel.
Goldemberg J. 2011. Antártica e as mudanças globais: um desafio para a humanidade. São Paulo, Edgard Blucher.

Harmata K, Olech M. 1991. Transect for aerobiological studies from Antarctica to Poland. Grana 30: 458-463.

Héguy L, Garneau M, Goldberg MS, Raphoz M, Guay F, Valois M. 2008. Associations between grass and weed pollen and emergency department visits for asthma among children in Montreal. Environmental Research 106: 203-211.

Linskens HF, Bargagli R, Cresti M, Focardi S. 1993. Entrapment of longdistance pollen grains by various moss species in coastal Victoria Land, Antatctica. Polar Biology 13: 81-87.

Magalhães N, Evangelista H, Tanizaki-Fonseca K, Meirelles MSP, Garcia CAE. 2011. A multivariate analysis of Antarctic sea ice since 1979. Climate Dynamics 38: 1115-1128.

Parnikoza I, Kozeretska I, Kunakh V. 2011. Vascular plants of the maritime Antarctic: Origin and adaptation. American Journal Plant Science 2: 381-395.

Potocki M, Mayewski PA, Kurbatov AV, et al. 2013. Short term arsenic deposition record from Detroit Plateau, Antarctic peninsula. In: 21th Annual Harold W. Borns, Jr. Symposium, 2013, Orono, Maine.

Schwanck F, Simões JC, Handley M, et al. 2016. Drilling, processing and first results for Mount Johns ice core in West Antarctica Ice Sheet. Brazilian Journal of Geology 46: 29-40.

Sotille ME, Bremer UF, Simões JC. 2016. Avanço e retração de área glacial no extremo norte da península Trinity, Antártica, entre 1988 e 2015. Revista do Departamento de Geografia 31: 72-81.

Souza Junior E, Rosa KK, Simões JC. 2016. Consequences of rapid environmental changes in the Arctic. Revista Brasileira de Geografia Física 9: 1137-1156.

Vergamini S, Ramos AJK, Duso L, Sbersi F, Maffazzoli FT. 2006. Identificação de tipos polínicos não registrados nos estudos aeropalinológicos do Brasil. Ciência Rural, Santa Maria 14: 1674-1680. 